\title{
Determinantes da Defasagem na Divulgação das Demonstrações Contábeis das Companhias Abertas Brasileiras*
}

\section{Determinants of Disclosure Timing for Financial Statements of Brazilian Public Companies}

\author{
Guilherme Kirch \\ Professor Adjunto do Departamento de Ciências Administrativas da Universidade Federal do Rio Grande do Sul \\ E-mail: gkirch@ea.ufrgs.br \\ João Batista Nast de Lima \\ Professor Adjunto do Instituto de Ciências Sociais Aplicadas da Universidade Feevale \\ E-mail: jnast@feevale.br \\ Paulo Renato Soares Terra \\ Professor Adjunto do Departamento de Ciências Administrativas da Universidade Federal do Rio Grande do Sul \\ E-mail: prsterra@ea.ufrgs.br
}

Recebido em 30.10.2011- Aceito em 3.11.2011 - $3^{a}$. versão aceita em 16.10.2012

\section{RESUMO}

Este trabalho investiga os fatores determinantes da defasagem na divulgação das demonstrações contábeis, trimestrais e anuais, das companhias brasileiras cujas ações compuseram o Índice da Bolsa de Valores de São Paulo (IBOVESPA) no período 1997/1-2009/2. Os fatores determinantes foram agrupados em quatro dimensões: complexidade das operações, características de governança corporativa, nível de assimetria informacional, e custos proprietários e conteúdo dos demonstrativos. Com uma amostra final de 83 companhias ( 1585 observações), foram examinados, por meio de métodos de dados em painel, os efeitos de 13 variáveis explicativas, tais como alavancagem de controle, tamanho da companhia, nível de governança corporativa, propriedade institucional, consolidação das demonstrações, volatilidade e prejuízo, sobre a defasagem na divulgação das demonstrações contábeis. Os principais resultados encontrados sugerem que a divulgação de demonstrativos consolidados e/ou que reportam prejuízos impacta positivamente a defasagem esperada, corroborando as hipóteses de que a maior complexidade das operações e o conteúdo dos demonstrativos (nesse caso, "más notícias") afetam positivamente a defasagem na divulgação. A variável alavancagem de controle, por sua vez, mostrou-se negativamente relacionada à defasagem, sugerindo que pode haver uma relação de substituição entre essas variáveis. Contrariando as expectativas teóricas, a variável volatilidade apresentou coeficientes positivos e estatisticamente significantes. No entanto, ao utilizar o método de variáveis instrumentais para obter estimativas consistentes na presença de simultaneidade entre a volatilidade e a defasagem na divulgação, a variável volatilidade apresentou coeficiente negativo e estatisticamente não diferente de zero.

Palavras-chave: Evidenciação. Demonstrações contábeis. Defasagem. Governança corporativa. Métodos de dados em painel.

\section{ABSTRACT}

This work examines the determining factors affecting the timing of disclosures in quarterly and annual financial statements of Brazilian companies with shares that are listed on the Sao Paulo Stock Exchange with shares that composed the São Paulo Stock Exchange Index (IBOVESPA) during the period 1/1997 - 2/2009. The determining factors were grouped into the following four dimensions: the complexity of operations, the characteristics of corporate governance, the level of information asymmetry, and the proprietary costs and statement content. With a final sample of 83 companies (1585 observations), the effects of 13 explanatory variables on the timing of disclosures in financial statements were examined using panel data methods; the variables examined included leverage control, company size, level of corporate governance, institutional ownership, financial statement consolidation, volatility, and losses. The main findings suggest that disclosing consolidated statements and/or statements that include losses has a positive effect on the timing of the disclosure, corroborating the hypothesis that disclosure timing is positively affected by greater complexity in operations and by the content of the statements (in this case, "bad news"). Control of the leverage variable, in turn, was shown to be negatively related to disclosure timing, suggesting that there may be a substitution relationship between these variables. Contrary to theoretical expectations, volatility displayed positive and statistically significant coefficients. However, upon the application of the instrumental variables method to obtain consistent estimates when there is simultaneity between volatility and disclosure timing, the volatility variable exhibited a negative coefficient and was statistically non-significant.

Keywords: Disclosures. Financial statements. Timing. Corporate governance. Panel data methods. 


\section{INTRODUÇÃO}

A alocação eficiente de recursos na economia consiste em direcionar os fluxos de recursos disponíveis para projetos de investimentos economicamente viáveis. Neste processo de alocação, a informação exerce um papel relevante entre os agentes envolvidos (poupador e tomador de recursos). As práticas de evidenciação contábil (disclosure corporativo), ao proverem seus usuários com informações úteis e confiáveis sobre as operações e o processo de gestão da companhia, constituem-se, portanto, em uma importante condição para o funcionamento de um mercado de capitais eficiente. Em função disto, as companhias são impelidas a fornecer um nível mínimo de disclosure obrigatório, através de instrumentos contábeis (e.g. demonstrativos, notas explicativas, relatório da administração, entre outros).

O principal elo entre a teoria econômica e a contabilidade contemporânea trata da noção de que a firma que se compromete a fornecer o nível mais elevado de disclosure deve ter menor custo de capital induzido pela existência de assimetrias informacionais ${ }^{1}$. O aumento dos níveis de disclosure reduz as assimetrias informacionais entre a companhia e seus acionistas, ou entre potenciais compradores e vendedores de ações. Isto, por sua vez, reduz o desconto pelo qual as companhias vendem as suas ações e reduz o custo de capital delas (Diamond \& Verrecchia, 1991; Baiman \& Verrecchia, 1996).

Em relação à relevância das demonstrações contábeis obrigatórias, diversos estudos empíricos mensuraram o impacto da informação contábil na precificação das ações como forma de verificar a relevância do conteúdo informacional dos relatórios contábeis no mercado de capitais. Destacam-se os estudos de Ball e Brown (1968), Beaver (1981) e Brown e Warner (1980, 1985). No Brasil, apesar da escassez de investigação empírica, destacam-se os estudos de Schiehll (1996), Prux Jr. (1998), Lopes (2002), Lima e Terra (2005) e Terra e Lima (2006). A partir da constatação de retornos anormais significativos na data de divulgação das demonstrações contábeis, tais estudos permitem concluir que a informação contábil afeta os preços das ações e, portanto, apresenta relevância para o mercado de capitais.

A utilidade da informação contábil, no entanto, não está relacionada apenas a sua natureza e conteúdo, mas também ao momento em que é divulgada (tempestividade). Informações de alta qualidade e confiabilidade podem deixar de ser úteis (influir no processo decisório) se não divulgadas no momento apropriado. Portanto, a qualidade do disclosure também deve ser medida pela rapidez com que os demonstrativos contábeis são disponibilizados ao público. Com base nessas considerações formulou-se o seguinte problema de pesquisa: Quais são os determinantes da defasagem na divulgação das demonstrações contábeis das companhias brasileiras?

O principal objetivo do estudo é fornecer evidências acerca dos determinantes da defasagem das companhias brasileiras de capital aberto. Para alcançar esse objetivo, foram analisadas as demonstrações contábeis, trimestrais e anuais, das companhias brasileiras cujas ações compuseram o Índice da Bolsa de Valores de São Paulo (IBOVESPA) no período 1997/1 - 2009/2. A defasagem é definida como o período de tempo transcorrido entre a data de encerramento do exercício e a data de divulgação das respectivas demonstrações contábeis, de forma similar aos estudos de Chambers e Penman (1984), Sengupta (2004) e Velury e Jenkins (2006).

Este trabalho contribui para a literatura da evidenciação contábil de diversas formas. Primeiramente, por abordar como os gestores decidem quando divulgar os demonstrativos contábeis trimestrais e anuais das suas companhias, uma dimensão de estudo ainda incipiente no Brasil. Em relação aos aspectos metodológicos, utilizou-se, entre outros métodos de estimação, o modelo de regressão Poisson, o qual pode ser considerado o mais apropriado, dado que a variável dependente assume somente valores inteiros não negativos. Finalmente, acredita-se que os resultados deste estudo podem ser úteis aos órgãos reguladores e de classe (Comissão de Valores Mobiliários, Conselho Federal de Contabilidade, Instituto dos Auditores Independentes do Brasil, entre outros) no sentido de contribuir com o entendimento dos fatores associados com a defasagem temporal dos demonstrativos contábeis no mercado de capitais brasileiro.

Os resultados encontrados indicam que o modelo proposto explica uma parcela não desprezível da variação da defasagem na divulgação dos demonstrativos financeiros. Das 13 variáveis explicativas representativas das quatro dimensões teóricas (complexidade, governança corporativa, assimetria informacional, e custos proprietários e conteúdo dos demonstrativos), três apresentaram coeficientes estatisticamente significantes em praticamente todas as regressões realizadas: demonstrações consolidadas, alavancagem de controle e prejuízo. O restante do artigo está estruturado da seguinte forma: na próxima seção é apresentada uma breve revisão da literatura; na seção 3 detalha-se o método de pesquisa, as variáveis utilizadas e o modelo estimado; e, por fim, nas seções 4 e 5 encontram-se, respectivamente, as análises dos resultados e considerações finais acerca do estudo.

\section{REFERENCIAL TEÓRICO E EMPÍRICO}

\subsection{Assimetria Informacional e o Papel do Disclosure.}

De acordo com Akerlof (1970), a assimetria de informações pode ser caracterizada como a situação na qual as partes de uma transação não possuem toda a informação necessária para averiguar se os termos do arranjo que está sendo proposto são comumente aceitáveis e serão implementados, bem como para avaliar o desempenho individu- 
al dos envolvidos. Mercados caracterizados pela existência de assimetrias de informação entre seus participantes no que se refere ao(s) objeto(s) de negociação podem não funcionar corretamente e, em casos extremos, podem deixar de existir (Lemons Principle).

Um dos maiores desafios de uma economia consiste na canalização dos recursos dos poupadores para as melhores oportunidades de investimentos. Nesse contexto, o mercado de capitais desempenha um papel fundamental: criar condições para que demandantes (tomadores) e ofertantes (poupadores) transacionem recursos ao menor custo possível. A relação entre poupadores e tomadores, no entanto, é normalmente caracterizada, entre outros, pelos seguintes aspectos: a) os tomadores tipicamente têm mais informações que os poupadores acerca do uso dos recursos (assimetria de informação); e b) uma vez que os poupadores tenham repassado seus recursos, os tomadores possuem incentivos para expropriá-los, visto que seus atos não podem ser plenamente monitorados (moral hazard). Tais características, relacionadas à questão informacional, podem criar dificuldades para o correto funcionamento do mercado de capitais.

Com o intuito de mitigar os problemas oriundos da existência de assimetrias informacionais no mercado de capitais e, dessa forma, permitir seu melhor funcionamento, criaram-se mecanismos (externos e internos) para incentivar a divulgação de informações privadas por parte das companhias e para permitir um monitoramento mais efetivo dos atos dos seus gestores por parte dos demais stakeholders (partes interessadas). Entre estes mecanismos destacase o disclosure obrigatório, isto é, a divulgação do conjunto mínimo de informações exigido pela legislação pertinente e pelos órgãos reguladores competentes.

Além do disclosure obrigatório, há outras informações de caráter voluntário e cuja divulgação, no Brasil, é recomendada pela Comissão de Valores Mobiliários (CVM), pela Bolsa de Valores de São Paulo (Bovespa) e/ou pelo Instituto Brasileiro de Governança Corporativa (IBGC). Tais informações têm caráter complementar e, em conjunto com as informações obrigatórias, visam facilitar a tomada de decisão de seus usuários, tornar mais transparente o processo de gestão das companhias e reduzir ainda mais as assimetrias informacionais entre os participantes do mercado.

De acordo com Healy e Palepu (2001), as consequências econômicas do disclosure para o mercado de capitais são: a) o aumento da liquidez das ações; e b) redução do custo de capital. Neste sentido, Kim e Verrecchia (1994) comentam que o disclosure reduz as assimetrias informacionais entre os investidores mais informados (sofisticados) e os pouco informados (não sofisticados). Com o aumento dos níveis de disclosure, os investidores sentem que o preço das ações é justo e, consequentemente, a liquidez aumenta. Healy, Hutton, e Palepu (1999) e Leuz e Verrecchia (2000) fornecem evidências empíricas de que o disclosure é positivamente associado com a liquidez do mercado de ações.

Em relação à redução do custo de capital, diversos estudos, entre eles os de Diamond e Verrecchia (1991), Botosan (1997), Healy e Palepu (2001), Easley, Hvidkjaer, e O’hara
(2002), Botosan e Plumlee (2002), Easley e O’hara (2004), Bailey, Karolyi, e Salva (2006), Lambert, Leuz, e Verrecchia (2007), sugerem (e evidenciam) uma relação entre a qualidade (ou nível) da informação contábil e os retornos dos ativos ou, de forma alternativa, o custo de capital das companhias. A intuição econômica que sustenta tal relação é a de que as informações contábeis são vitais para redução da assimetria de informações existente entre os agentes do mercado, mitigando o problema da seleção adversa e, em função disto, os agentes exigiriam um retorno esperado maior das companhias que divulgam informações em menor número e qualidade (maior risco informacional) em relação àquelas que divulgam mais e melhores informações (menor risco informacional). Os gestores teriam, portanto, incentivos para aumentar o nível de disclosure para reduzir os problemas de assimetria e, consequentemente, o custo de capital.

No Brasil, Malacrida e Yamamoto (2006) analisaram a relação entre o nível de disclosure de informações contábeis e a volatilidade dos retornos das ações de 40 companhias que compuseram o Índice da Bolsa de Valores de São Paulo (IBOVESPA) no ano de 2002. Os resultados sugerem que as companhias com maior nível médio de disclosure apresentam menor volatilidade média dos retornos de suas ações. Alencar (2005) investigou se o nível de disclosure é fator determinante do custo de capital próprio (medido pelo beta do modelo Capital Asset Pricing Model - CAPM) em uma amostra de 222 companhias brasileiras no ano de 2003. Os resultados mostram que o nível de disclosure não afeta de maneira estatisticamente significante o beta de mercado das companhias. A falta de relação entre o nível de disclosure e o custo do capital próprio, segundo a autora, poderia ser decorrente de limitações da proxy utilizada para nível de disclosure. Lima (2009) analisou a relação entre o nível de disclosure voluntário e o custo de capital de terceiros em uma amostra de 23 companhias no período 2000-2004. Corroborando a hipótese formulada pelo autor, os resultados (estimador pooling) indicam que o nível de disclosure voluntário tem uma relação inversa com o custo de capital de terceiros. Em suma, os resultados relatados para a realidade brasileira sugerem que a adoção de maiores níveis de disclosure poderá trazer benefícios para as companhias, tais como: menor volatilidade e menor custo de capital, em linha com estudos realizados em outros países.

\subsection{Determinantes da Defasagem Temporal dos Demonstrativos Financeiros.}

De acordo com Givoly e Palmon (1982), atrasos na divulgação dos demonstrativos contábeis provavelmente aumentam a incerteza associada com decisões para as quais tais demonstrativos provêm informações relevantes. Chambers e Penman (1984) apontam que, quanto mais defasada for a divulgação dos demonstrativos contábeis, maior a possibilidade de serem substituídos por outras fontes informativas. Assim, quanto mais retardada for a divulgação dos demonstrativos contábeis, menor tenderá a ser a volatilidade dos retornos das ações na data de divulgação, visto que o conteúdo informacional das demonstrações tenderá a ser, ao menos parcialmente, antecipado. Nesta mesma linha de 
raciocínio, Sengupta (2004) ressalta que a utilidade das informações contábeis aos participantes do mercado deve ser uma função não somente da natureza da informação, mas também de quando é divulgada.

Conforme Sengupta (2004, p. 459), a literatura acerca do disclosure corporativo geralmente afirma que a estratégia ótima de disclosure será determinada pelos custos e benefícios associados. Com base nesses custos e benefícios, os gestores determinariam, entre outras coisas, a natureza e o conteúdo das informações, bem como a data ideal e a mídia apropriada para divulgação. Esse argumento, portanto, sugere que os gestores deveriam determinar a data de divulgação dos demonstrativos contábeis baseados na avaliação dos potenciais benefícios e custos de divulgar as informações mais rapidamente. Tais custos e benefícios estão, provavelmente, relacionados às características da companhia e seu ambiente competitivo e ao conteúdo dos demonstrativos contábeis no período em questão.

Entre as características específicas das companhias e de seu ambiente competitivo que, segundo a literatura pertinente, poderiam influenciar a defasagem na divulgação das demonstrações contábeis estão aquelas relacionadas à complexidade das operações (ou complexidade contábil), aos custos de litígio, aos custos proprietários (proprietary costs) e à governança corporativa. De acordo com Givoly e Palmon (1982, p. 491):

The single most important determinant of the timeliness of the earnings announcement is the length of the audit. Three main factors are likely to decide the total input required for an external audit: the size of the company, the quality of its internal control system, and the complexity of its operation (...) At the same time, big corporations may be more closely watched by investors and therefore under greater pressure to release information on a timely basis.

Givoly e Palmon (1982), Chambers e Penman (1984) e Sengupta (2004) encontram evidências de que a defasagem na divulgação das demonstrações contábeis é inversamente relacionada com o tamanho da companhia, provendo suporte para o argumento de que as grandes companhias sofrem maior pressão do público (investidores em especial) para divulgar mais rapidamente seus demonstrativos contábeis. Quanto à complexidade das operações, Sengupta (2004) apresenta evidências de que companhias que operam em múltiplos segmentos e/ou que reportam itens especiais tendem a divulgar mais tardiamente suas demonstrações contábeis. Além disso, o referido autor encontrou uma relação positiva e estatisticamente significante entre a defasagem na divulgação e o número de aquisições realizadas pela companhia no período. Esses resultados corroboram a hipótese de que a complexidade das operações afeta positivamente a defasagem na divulgação das demonstrações contábeis. Givoly e Palmon (1982) utilizam o crescimento médio das vendas e a razão estoques sobre ativos como proxies para complexidade contábil mas não encontram evidências conclusivas da relação dessas variáveis com a defasagem na divulgação.

Conforme Sengupta (2004), disclosures tempestivos provavelmente têm um papel importante na redução dos cus- tos de litígio. Skinner (1994), por exemplo, argumenta que, para evitar grandes declínios nos preços das ações na data de divulgação dos resultados e, dessa forma, reduzir custos potenciais com processos legais (por parte de acionistas), os gestores têm incentivos para anunciar antecipadamente resultados negativos não esperados. Segundo o referido autor, esta estratégia é, provavelmente, a melhor alternativa disponível por pelo menos dois motivos: i) o disclosure antecipado enfraquece o argumento do(s) reclamante(s) de que os gestores falharam em divulgar a informação rapidamente; e ii) quanto menor o período de "não divulgação" menor o número de reclamantes e, portanto, menor o custo esperado do litígio (evidências serão apresentadas na sequência).

Ainda em relação aos custos de litígio, Sengupta (2004) argumenta que, ao contrário dos gestores, os membros independentes do conselho pouco têm a ganhar e muito a perder (custos com processos e/ou perda de reputação) com a postergação da divulgação das demonstrações contábeis e, dessa forma, teriam incentivos para encorajar uma política de disclosure tempestivo. Quanto às evidências, Sengupta (2004) encontra uma relação negativa e estatisticamente significante entre o percentual de diretores não gestores da companhia e a defasagem na divulgação, resultado que provê respaldo ao seu argumento. Além disso, o referido autor apresenta evidências de que companhias que atuam em setores com alta probabilidade de litígio (setores de alta tecnologia) tendem a divulgar mais rapidamente seus demonstrativos contábeis.

De acordo com Verrecchia (1990), os custos proprietários podem obstruir a evidenciação voluntária ou a redução da assimetria informacional entre gestores e stakeholders pois, em um mercado competitivo, disponibilizar mais informações equivale a permitir que os competidores da companhia conheçam o seu negócio com maior profundidade. Isto poderia, portanto, afetar a competitividade da companhia (Verrecchia, 1983). Nesse caso, a retenção de informações relevantes ou o adiamento da divulgação destas seria decidido em benefício dos acionistas. Em termos de evidências, Sengupta (2004) encontra uma relação positiva e estatisticamente significante entre a defasagem na divulgação e a concentração das vendas no setor (proxy para custos proprietários, ver Bamber \& Cheon, 1998, p. 171), corroborando a hipótese de que custos proprietários criam incentivos para adiar a divulgação de informações relevantes.

Companhias comprometidas com melhores práticas de governança corporativa e sob maior escrutínio do mercado estariam, a priori, mais dispostas a praticar uma política de disclosure tempestivo (supondo uma relação complementar entre estas variáveis). Dessa forma, é razoável supor que firmas listadas em segmentos especiais (como o Nível 1, Nível 2 e Novo Mercado da Bovespa) e/ou aquelas mais ativamente negociadas tendam a divulgar mais rapidamente seus demonstrativos. De acordo com Sengupta (2004), a demanda dos investidores por disclosure tempestivo deve ser uma função crescente do volume negociado, pois os investidores estariam mais preocupados em receber informações daquelas companhias nas quais investem com maior 
frequência e intensidade. Assim, deve haver uma relação negativa entre a defasagem na divulgação de determinada companhia e o volume negociado de suas ações no mercado. No que tange a estrutura de propriedade, o referido autor argumenta que, quando a propriedade é dispersa, o disclosure é o método mais efetivo de comunicar informação privada e, portanto, haveria uma relação negativa entre a defasagem e a dispersão acionária. Velury e Jenkins (2006) argumentam que, se os investidores institucionais são melhores monitores da gestão do que investidores individuais, então deve-se esperar uma relação negativa entre a defasagem na divulgação e o nível de propriedade institucional. Quanto às evidências empíricas, Sengupta (2004) e Velury e Jenkins (2006) constataram que a defasagem na divulgação é negativamente relacionada com o nível de propriedade institucional e positivamente relacionada com a concentração de propriedade. Além disso, Sengupta (2004) encontra uma relação negativa entre a defasagem na divulgação e o volume negociado.

Por fim, o conteúdo dos demonstrativos contábeis também pode ter um papel relevante na determinação da data de divulgação destes. Como mencionado anteriormente, Skinner (1994) sugere que os gestores têm incentivos para anunciar antecipadamente resultados negativos não esperados ("más notícias"). Por outro lado, Begley e Fischer (1998), com base em uma revisão da literatura anterior, mencionam que, atrasando a divulgação das "más notícias", os gestores podem obter benefícios por: a) estarem aptos a completar negócios em condições mais favoráveis antes da divulgação; b) terem mais tempo para preparar respostas às críticas e um plano para reverter a má performance; e c) terem mais tempo para encontrar formas de reverter as "más notícias" por meio da manipulação dos resultados (accruals or earnings management). Em termos de evidências empíricas, Whittred (1980), Kross (1981), Givoly e Palmon (1982), Chambers e Penman (1984), Begley e Fisher (1998), Sengupta (2004) e Velury e Jenkins (2006) constataram que os gestores tendem a divulgar as "más notícias" mais tardiamente. Esses resultados fornecem sustentação para a hipótese de que os benefícios de retardar a divulgação das "más notícias" superam possíveis custos associados (como, por exemplo, os custos de litígio).

\section{MÉTODO DE PESQUISA}

\subsection{Definição de Variáveis.}

A variável dependente no presente estudo é o período de tempo transcorrido entre a data de encerramento do exercício e a data de divulgação das respectivas demonstrações contábeis. Por "exercício" entende-se o trimestre no caso das Informações Trimestrais (ITR) e o ano no caso das Demonstrações Financeiras Padronizadas (DFP). Em todos os casos, o período de referência para os valores ob- tidos é o respectivo trimestre calendário. A divulgação das DFP é regulamentada pelo artigo 28, inciso II, da Instrução CVM 480/2009, que estabelece como prazo máximo de divulgação 3 meses após o encerramento do exercício social. A divulgação das ITR é regulamentada pelo artigo 29, inciso II, e pelo artigo 65 da Instrução CVM 480/2009, que estabelece como prazo máximo de divulgação 45 dias após a data de encerramento de cada trimestre ${ }^{2}$.

Tabela 1 Dimensões investigadas e definição das variáveis explicativas

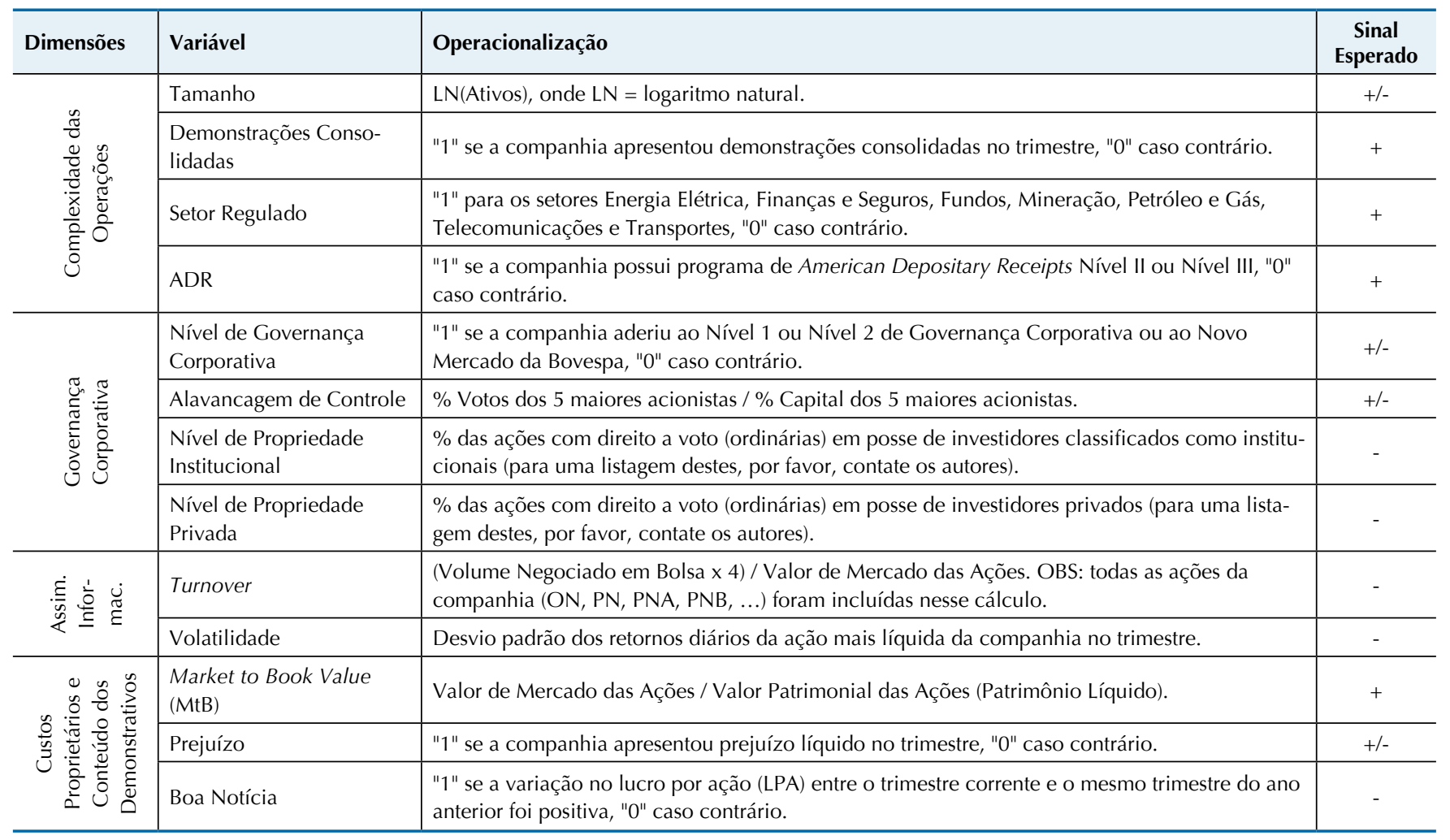

${ }^{2}$ Observe que a norma (Instrução CVM 480/2009) é recente e, portanto, poderia levantar dúvidas quanto a possíveis alterações no prazo máximo de divulgação das ITRs e DFPs ao longo do período de estudo. Dessa forma, cabe mencionar que não houve alteração nesses prazos (ver Instruções CVM 202/1993 e 351/2001). 
As variáveis explicativas foram selecionadas com base na revisão de literatura anteriormente delineada. Observou-se também a disponibilidade de dados e as características específicas do mercado de capitais brasileiro. Inicialmente, foram definidas quatro dimensões que, conforme a literatura, potencialmente afetam a defasagem na divulgação das demonstrações contábeis: i) complexidade das operações da companhia; ii) características de governança corporativa; iii) nível de assimetria informacional no mercado acionário; e iv) custos proprietários e conteúdo dos demonstrativos. Para implementação empírica das quatro dimensões referidas, foram selecionadas variáveis que fossem proxies adequadas para os fatores subjacentes. Um sumário das variáveis explicativas, contendo definição resumida, operacionalização e expectativa quanto ao sinal da relação com a variável dependente, é apresentado na Tabela 1.

I) Para representar a complexidade das operações foram selecionadas as variáveis:

- Tamanho: mede o porte da companhia e, consequentemente, a complexidade de suas operações. No entanto, como ressaltam Givoly e Palmon (1982), grandes corporações provavelmente estão sob maior escrutínio dos investidores e, dessa forma, sob maior pressão para divulgação tempestiva de suas demonstrações;

- Demonstrações Consolidadas: a consolidação das demonstrações financeiras de um grupo de companhias é certamente um fator de maior complexidade;

- Setor Regulado: companhias de setores regulados estão sujeitas ao escrutínio mais severo dos órgãos reguladores (por exemplo, Banco Central no caso dos bancos), o que pode aumentar o grau de complexidade da contabilidade delas;

- ADR: as companhias que possuem programas de American Depositary Receipts Nível II ou Nível III devem converter as suas demonstrações contábeis para o padrão contábil norte-americano (United States Generally Accepted Accounting Principles - USGAAP). Essa conversão representa um aumento na complexidade da contabilidade dessas empresas.

II) Para representar as características de governança corporativa foram escolhidas as seguintes variáveis:

- Nível de Governança Corporativa: a companhia que aderiu voluntariamente aos níveis diferenciados de governança corporativa patrocinados pela Bovespa está se comprometendo formalmente com um conjunto de regras diferenciado no que diz respeito à sua relação com os investidores. Se há uma relação complementar entre a adesão aos níveis diferenciados e a prática de disclosure tempestivo, então espera-se uma relação negativa entre esta variável explicativa e a defasagem na divulgação das demonstrações contábeis. Por outro lado, se a relação entre a adesão aos níveis diferenciados e a prática de disclosure tempestivo for substituta, então espera-se uma relação positiva entre esta variável explicativa e a dependente;

- Alavancagem de Controle: mede a relação entre o percentual de votos dos cinco principais acionistas e o percentual dos seus direitos aos fluxos de caixa. Nesse sentido indica a propensão dos controladores para extrair benefícios privados do controle, característica importante do mercado de capitais brasileiro (Leal \& Saito, 2003; Dyck \& Zingales, 2004). Novamente, o sinal esperado da relação entre esta variável explicativa e a variável defasagem na divulgação dependerá da natureza desta relação: se complementar (sinal positivo); se substituta (sinal negativo);

- Propriedade Institucional: se os investidores institucionais exercem um papel de monitoramento mais intenso sobre as companhias das quais são acionistas do que os acionistas em geral, deve-se esperar uma relação negativa entre o nível de propriedade institucional e a defasagem na divulgação dos demonstrativos;

- Propriedade Privada: companhias privadas estão menos sujeitas às influências políticas, tanto na condução dos seus negócios quanto na indicação dos membros do conselho de administração. Ao mesmo tempo, tais companhias têm uma maior necessidade de legitimação e, dessa forma, tenderiam a incorporar as demandas do ambiente mais rapidamente vis-à-vis às companhias públicas. Dessa forma, espera-se uma relação negativa entre a defasagem na divulgação e o nível de propriedade privada.

III) Para representar o grau de assimetria de informações entre a companhia e o mercado foram selecionadas as seguintes variáveis:

- Turnover: razão entre o volume negociado das ações da companhia ao longo do exercício e seu valor de mercado no final do mesmo exercício. Indiretamente sinaliza o número de investidores que estão acompanhando mais estreitamente as atividades da companhia, demandando informações a seu respeito. Como em Sengupta (2004), espera-se uma relação negativa entre esta variável explicativa e a defasagem na divulgação dos demonstrativos contábeis;

- Volatilidade: corresponde à variabilidade dos retornos diários da ação mais líquida da companhia no respectivo exercício (trimestre). Uma volatilidade elevada sugere maiores incertezas quanto às operações da companhia e, provavelmente, maior demanda por disclosure tempestivo. Cabe mencionar que a volatilidade pode ser determinada, em parte, pela qualidade da informação contábil. Lambert, Leuz, e Verrecchia (2007), por exemplo, desenvolvem um modelo consistente com o Capital Asset Pricing Model (CAPM) e mostram que um aumento na qualidade da informação contábil reduz a variância estimada dos fluxos de caixa da firma. Como o disclosure tempestivo é um dos determinantes da qualidade da informação contábil, a defasagem na divulgação e a volatilidade dos retornos da firma podem ser determinadas simultaneamente. Nesse caso, o método de variáveis instrumentais deve ser utilizado para estimação consistente dos parâmetros do modelo.

IV) Para representar os custos proprietários e o conteúdo dos demonstrativos contábeis foram escolhidas as seguintes variáveis: 
- Market to Book Value : razão entre o valor de mercado da companhia e seu valor contábil. Reflete as oportunidades de crescimento da companhia e, possivelmente, o montante de custos proprietários. De acordo com Bamber e Cheon (1998, p. 171), quanto maiores forem as oportunidades de crescimento da companhia, mais relutantes são os gestores para revelar informações que possam reduzir o valor dessas oportunidades. Portanto, espera-se que companhias com maiores oportunidades de crescimento retardem, ao máximo, a divulgação de informações relevantes sobre o negócio;

- Prejuízo: a constatação de um prejuízo pode causar o retardo na divulgação do que seriam notícias negativas a respeito da companhia. Como destacado na revisão empírica, diversos estudos constataram que os gestores tendem a retardar a divulgação de "más notícias". Skinner (1994), por outro lado, sugere que os gestores têm incentivos para anunciar antecipadamente resultados negativos não esperados ("más notícias") para minimizar custos de litígio;

- Boa Notícia: se a divulgação das demonstrações contábeis causar uma surpresa positiva no mercado é possível que a sua defasagem seja menor do que em situações em que a surpresa não seja tão favorável. Para determinar essa "surpresa" optou-se por utilizar como proxy a variação do Lucro por Ação (LPA) entre o trimestre corrente e o mesmo trimestre do ano anterior. Se esta variação for positiva, isto é, se houve um aumento no LPA, considera-se que uma boa notícia está sendo comunicada ao mercado.
Na Tabela 2 são apresentadas estatísticas descritivas para a variável dependente em termos anuais e trimestrais. Antes de qualquer análise, é importante ter em mente que o ano de 2009 possui apenas informações do primeiro e segundo trimestres e que o ano de 1997 possui um número relativamente pequeno de observações. Com base na referida tabela, percebe-se que a defasagem média na divulgação das demonstrações da amostra gira em torno de 44 dias. Ao longo dos anos, no entanto, essa média reduz-se sensivelmente, tendo diminuído aproximadamente em sete dias entre 1998 e 2008 . Quanto a defasagem por trimestre, observam-se valores médios semelhantes para os três primeiros trimestres do ano (em torno de 38 a 39 dias), enquanto que, no quarto trimestre, essa média é mais elevada (cerca de 63 dias). Isto se deve ao fato de que o quarto trimestre refere-se à divulgação das DFPs, para as quais o regulador concede um prazo mais generoso de divulgação, conforme mencionado na revisão de literatura.

Ainda com base na Tabela 2, observa-se que o percentual de atraso, isto é, o percentual de divulgações que ocorreram após o prazo legal, corresponde a $18 \%$ das divulgações analisadas. Assim como a média da defasagem, o percentual de atraso vem diminuindo sensivelmente ao longo dos anos (35\% de divulgações atrasadas em 1998 contra 7\% em 2008). Embora a elaboração das DFPs seja, em geral, mais complexa do que das ITRs, o percentual de atraso no quarto trimestre é de aproximadamente $6 \%$, menos de $1 / 3$ dos atrasos observados nos demais trimestres do ano. Isto reflete, em parte, o maior prazo concedido pelas autoridades para divulgação das primeiras $v i s-\grave{a}-v i s$ as últimas.

Tabela 2 Estatísticas descritivas para a variável dependente

\begin{tabular}{|c|c|c|c|c|c|c|c|c|c|}
\hline Ano & Obs & Média & Mediana & Desvio Padrão & $\%$ Atraso & Máximo & Mínimo & $1^{\circ}$ Percentil & $99^{\circ}$ Percentil \\
\hline 1997 & 11 & 56,91 & 51 & 14,63 & 64 & 82 & 35 & 35 & 82 \\
\hline 1998 & 63 & 50,44 & 47 & 23,38 & 35 & 114 & 13 & 13 & 114 \\
\hline 1999 & 105 & 47,61 & 47 & 19,28 & 42 & 147 & 13 & 14 & 99 \\
\hline 2000 & 116 & 44,69 & 45 & 17,54 & 30 & 92 & 13 & 13 & 92 \\
\hline 2001 & 133 & 48,00 & 45 & 18,99 & 32 & 115 & 10 & 11 & 102 \\
\hline 2002 & 132 & 45,20 & 43 & 18,48 & 20 & 110 & 10 & 11 & 105 \\
\hline 2003 & 124 & 43,53 & 42 & 18,05 & 14 & 93 & 9 & 10 & 92 \\
\hline 2004 & 127 & 43,28 & 41 & 17,60 & 13 & 90 & 8 & 12 & 90 \\
\hline 2005 & 146 & 43,11 & 40,5 & 15,95 & 9 & 89 & 10 & 11 & 89 \\
\hline 2006 & 149 & 44,65 & 42 & 16,98 & 13 & 95 & 6 & 7 & 92 \\
\hline 2007 & 177 & 42,43 & 41 & 14,62 & 11 & 91 & 5 & 6 & 91 \\
\hline 2008 & 204 & 43,57 & 42 & 17,22 & 7 & 90 & 7 & 16 & 89 \\
\hline 2009 & 98 & 40,01 & 43 & 7,09 & 9 & 50 & 16 & 16 & 50 \\
\hline Trimeste & Obs & Média & Mediana & Desvio Padrão & $\%$ Atraso & Máximo & Mínimo & $1^{\circ}$ Percentil & $99^{\circ}$ Percentil \\
\hline $1^{\circ}$ & 393 & 39,40 & 41 & 11,53 & 23 & 147 & 5 & 10 & 71 \\
\hline $2^{\circ}$ & 424 & 38,04 & 40 & 10,28 & 22 & 114 & 6 & 11 & 59 \\
\hline $3^{\circ}$ & 383 & 38,29 & 40 & 10,69 & 21 & 110 & 6 & 9 & 64 \\
\hline $4^{\circ}$ & 385 & 62,91 & 62 & 20,42 & 6 & 115 & 10 & 13 & 102 \\
\hline Total & 1585 & 44,48 & 43 & 17,29 & 18 & 147 & 5 & 11 & 92 \\
\hline
\end{tabular}


Estatísticas descritivas para as variáveis explicativas (quantitativas contínuas somente) são apresentadas na Tabela 3. Cabe destacar que as divulgações analisadas provêm, em média, de companhias com controle privado, com pequena participação institucional e cujos maiores acionistas utilizam-se da alavancagem do controle. A matriz de corre- lações das variáveis explicativas (quantitativas contínuas somente) é apresentada na Tabela 4. As correlações entre essas variáveis são, em geral, modestas, apresentando um máximo de 0,27 (entre Turnover e Volatilidade) e um mínimo de -0,33 (entre Tamanho e \% Propriedade Privada), sugerindo que problemas de multicolinearidade são de menor ordem.

Tabela 3 Estatísticas descritivas das variáveis explicativas quantitativas contínuas

\begin{tabular}{|c|c|c|c|c|c|c|c|c|}
\hline Variável & Obs & Média & Mediana & Desvio Padrão & Máximo & Mínimo & 1o Percentil & 99o Percenti \\
\hline Tamanho & 1585 & 16,57 & 16,52 & 1,45 & 20,31 & 12,22 & 13,93 & 19,90 \\
\hline Alavancagem Controle & 1585 & 1,61 & 1,57 & 0,53 & 3,00 & 0,91 & 0,97 & 2,84 \\
\hline \% Prop. Institucional & 1585 & 0,10 & 0,05 & 0,15 & 0,87 & 0,00 & 0,00 & 0,58 \\
\hline$\%$ Prop. Privada & 1585 & 0,88 & 1,00 & 0,24 & 1,00 & 0,06 & 0,15 & 1,00 \\
\hline Volatilidade (\%) & 1585 & 2,98 & 2,69 & 1,30 & 20,62 & 0,34 & 1,35 & 7,46 \\
\hline Market to Book Value & 1585 & 2,18 & 1,48 & 3,79 & 73,18 & $-26,42$ & 0,16 & 18,15 \\
\hline
\end{tabular}

Tabela 4

Matriz de correlação (Pearson) das variáveis explicativas quantitativas contínuas

\begin{tabular}{l|c|c|c|c|c|c}
\hline & Tamanho & $\mathbf{( 1 )}$ & (2) & (3) & (4) & (5) \\
\hline Alavancagem Controle (1) & $\mathbf{- 0 , 0 7}$ & & & & & \\
\hline \% Prop. Institucional (2) & $-0,03$ & $\mathbf{- 0 , 1 3}$ & & & & \\
\hline \% Prop. Privada (3) & $\mathbf{- 0 , 3 3}$ & $\mathbf{0 , 1 6}$ & $-0,03$ & & & \\
\hline Turnover (4) & $\mathbf{- 0 , 2 2}$ & $\mathbf{0 , 1 7}$ & $\mathbf{0 , 0 7}$ & $\mathbf{0 , 0 7}$ & & \\
\hline Volatilidade (5) & $\mathbf{- 0 , 1 6}$ & 0,01 & $\mathbf{0 , 0 9}$ & 0,02 & $\mathbf{0 , 2 7}$ & \\
\hline Market to Book Value & $\mathbf{- 0 , 0 7}$ & $\mathbf{- 0 , 1 0}$ & $\mathbf{- 0 , 0 7}$ & $\mathbf{0 , 1 5}$ & $\mathbf{0 , 0 4}$ & $\mathbf{- 0 , 0 5}$ \\
\hline
\end{tabular}

Em destaque (negrito) correlações significativas ao nível de 10\% ou menos.

\subsection{Caracterização da Amostra e Coleta de Dados}

Inicialmente, o período amostral compreendeu todos os trimestres entre 1995/1 e 2009/2 (ano/trimestre) ${ }^{3}$. A opção de iniciar o período amostral no ano de 1995 deve-se ao fato de que este é o primeiro ano após a implantação do Plano Real em julho de 1994. Em cada trimestre do período amostral, foram selecionadas, para fins de composição da amostra, as companhias que compuseram o Índice da Bolsa de Valores de São Paulo (IBOVESPA) naquele trimestre. Como o IBOVESPA é revisto quadrimestralmente, foi adotada a seguinte convenção:

a) $1^{\circ}$ trimestre $\rightarrow$ composição do IBOVESPA no $1^{\circ}$ quadrimestre (Janeiro/Abril);

b) $2^{\circ}$ trimestre $\rightarrow$ composição do IBOVESPA no $2^{\circ}$ quadrimestre (Maio/Agosto);

c) $3^{\circ}$ e $4^{\circ}$ trimestres $\rightarrow$ composição do IBOVESPA no $3^{\circ}$ quadrimestre (Setembro/Dezembro);

O critério empregado para seleção da amostra visou à satisfação dos seguintes requisitos: i) obter uma amostra das companhias mais negociadas na Bovespa e, consequentemente, representativa do mercado de capitais brasileiro; e ii) obter um número administrável de companhias, visto que a data de divulgação de suas demonstrações contábeis seria coletada manualmente junto aos Boletins Diários da Bovespa (BDI). Ao restringir-se a amostra àquelas compa- nhias que compuseram o IBOVESPA em cada trimestre pode-se satisfazer a ambos os requisitos simultaneamente, uma vez que as ações integrantes do referido índice respondem por, no mínimo, $80 \%$ dos negócios e do volume financeiro da Bovespa (BM\&FBovespa, 2010) e, ao mesmo tempo, o número de companhias às quais as ações integrantes se referem é limitado e perfeitamente administrável.

A amostra inicial era composta de 3080 observações de 112 diferentes companhias. Foram excluídas da amostra inicial as observações de companhias para as quais não foi possível obter todas as variáveis necessárias à investigação do problema (1483 observações) e as observações em que a defasagem na divulgação não se encontrava no intervalo de 0 a 150 dias (12 observações). Dados sobre a estrutura de propriedade (composição acionária) só estavam disponíveis a partir do ano de 1997 e, dessa forma, o período amostral teve de ser restringido a todos os trimestres entre 1997/1 e 2009/2 (50 trimestres). Das 1483 observações excluídas por indisponibilidade de dados, 863 (58\%) referemse a dados relativos a estrutura de propriedade. Após as exclusões, a amostra final contava com 1585 observações de 83 diferentes companhias, uma média de aproximadamente 19 observações por companhia. Com exceção da variável dependente, todos os dados necessários para construção das variáveis explicativas foram coletados da base de dados da Economática ${ }^{\mathbb{R}}$. 


\subsection{Modelo Empírico}

Para analisar os efeitos das variáveis explicativas anteriormente definidas sobre a defasagem na divulgação das demonstrações contábeis, estimou-se o seguinte modelo linear:

$$
Y_{i, t}=\alpha_{i}+\sum_{j=1}^{13} \beta_{j} X_{j i, t}+\sum_{k=2}^{4} \gamma_{k} T_{k}+\mu_{t}+\varepsilon_{i, t}
$$

Em que: $Y_{i, t}$ é a variável dependente (defasagem na divulgação das demonstrações) da $i$-ésima companhia no trimestre $t ; \alpha_{i}$ é o efeito específico não observado e constante no tempo da $i$-ésima companhia; $X_{j i, t}$ é a $j$-ésima variável explicativa da $i$-ésima companhia no trimestre $t ; T_{k}$ variável categórica (dummy) para o $k$-ésimo trimestre, $k=2,3$ ou 4; $\mu_{t}$ captura efeitos específicos de cada período (anos), sendo representado por um conjunto de dummies de período; $\beta_{j} \mathrm{e}$ $\gamma_{k}$ são parâmetros a serem estimados; e $\varepsilon_{i, t}$ é o termo de erro idiossincrático.

\section{RESULTADOS}

O modelo (1) será estimado por meio de métodos de dados em painel (panel data methods). Como a variável explicativa Setor Regulado é constante no tempo, utilizou-se o método de efeitos aleatórios, o qual, entre outras suposições, assume a ortogonalidade entre o efeito específico não observado $\left(\alpha_{i}\right)$ e as variáveis explicativas. Para obter estimativas consistentes na presença de correlação arbitrária entre o efeito específico não observado e as variáveis explicativas, foi utilizado também o estimador de Hausman-Taylor ${ }^{4}$. Dado que a variável dependente assume somente valores inteiros não negativos, estimaram-se também os parâmetros por meio do modelo de regressão Poisson (Poisson Regression Model $)^{5}$ com efeitos aleatórios. Esta última técnica de estimação, que pode ser considerada a mais adequada dada a natureza dos dados utilizados, não foi usada em estudos anteriores e, portanto, trata-se de uma inovação metodológica do presente estudo em relação aos demais.
Os resultados das estimações são apresentados na Tabela 5. Antes de qualquer análise, é importante atentar para os seguintes aspectos: (i) após estimar o modelo (1) pelo método de efeitos aleatórios, a análise dos resíduos indicou a presença de autocorrelação e, por isso, o modelo foi estimado novamente utilizando-se uma correção para erros com estrutura autorregressiva de ordem 1 [estimador efeitos aleatórios $\mathrm{AR}(1)$, coluna 2]; e (ii) os coeficientes do modelo de regressão Poisson possuem interpretação diferente dos coeficientes dos demais estimadores. De acordo com Wooldridge (2002, p. 648), os coeficientes do modelo de regressão Poisson são as semielasticidades da expectativa condicional da variável dependente em relação às variáveis explicativas. Assim, segundo o referido autor, para pequenas alterações na variável explicativa $x_{j}, \Delta x_{j}$, a alteração percentual na expectativa condicional da variável dependente, $E(y \mid x)$, é aproximadamente de $100 \times \beta_{j} \times \Delta x_{j}$.

Uma análise geral da Tabela 5 indica que, com poucas exceções, os resultados não diferem, qualitativamente, entre os estimadores. Isto, por sua vez, sugere que os resultados são robustos ao método de estimação escolhido e que possíveis problemas decorrentes de autocorrelação nos resíduos e correlação arbitrária entre o efeito específico não observado e as variáveis explicativas são de menor ordem.

Tabela 5 Resultados da estimação do modelo empírico

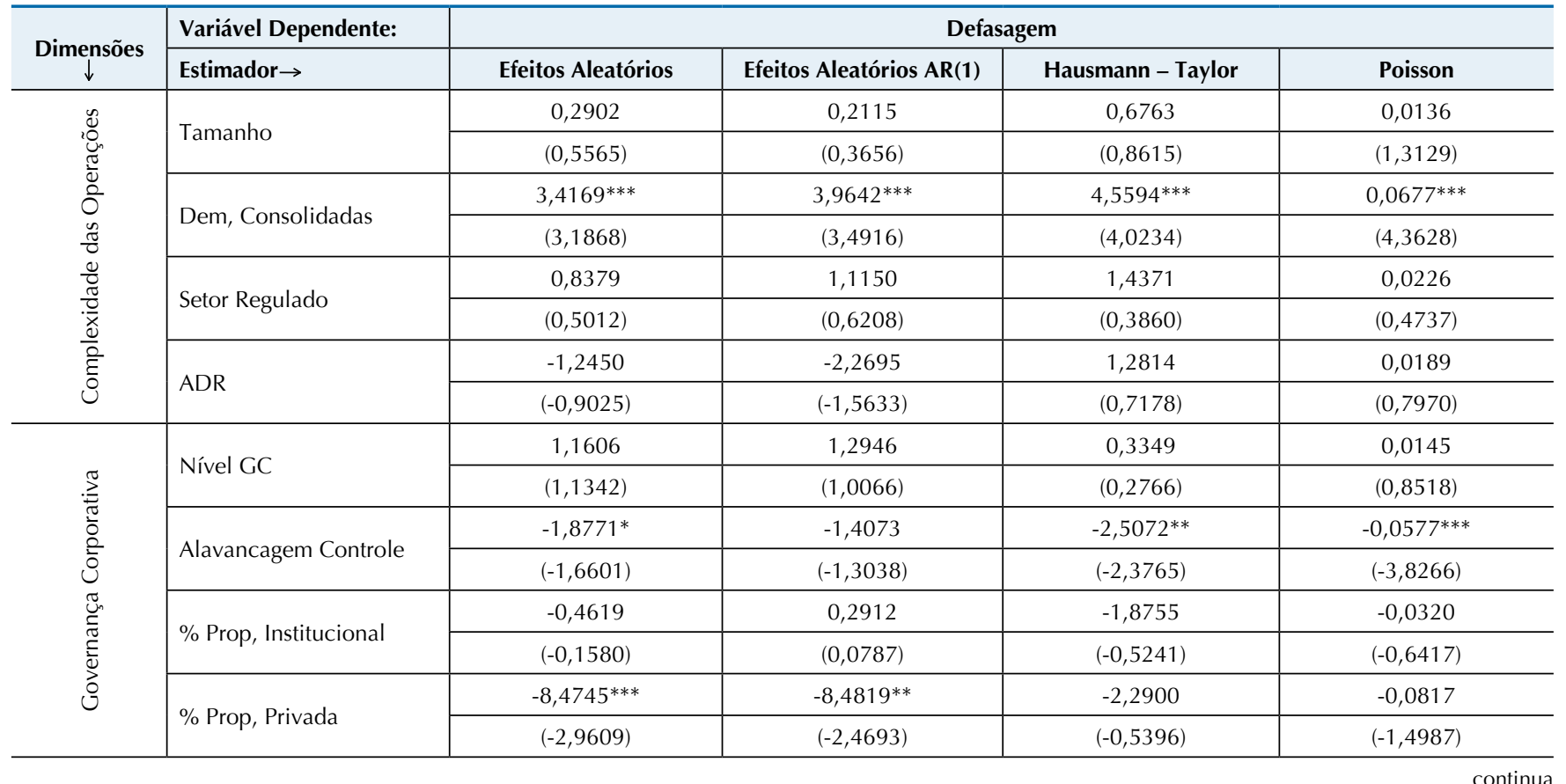




\begin{tabular}{|c|c|c|c|c|c|}
\hline \multirow{2}{*}{ Dimensões } & \multirow{2}{*}{$\begin{array}{l}\text { Variável Dependente: } \\
\text { Estimador } \rightarrow \\
\end{array}$} & \multicolumn{4}{|c|}{ Defasagem } \\
\hline & & Efeitos Aleatórios & Efeitos Aleatórios AR(1) & Hausmann - Taylor & Poisson \\
\hline \multirow{4}{*}{ 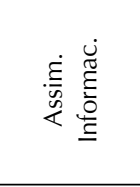 } & \multirow{2}{*}{ Turnover } & 0,0006 & 0,0003 & 0,0006 & $0,00002^{*}$ \\
\hline & & $(0,6643)$ & $(0,4018)$ & $(0,7109)$ & $(1,7993)$ \\
\hline & \multirow{2}{*}{ Volatilidade } & $1,6306^{* * *}$ & $1,4679^{* * *}$ & $1,4267^{* * *}$ & $0,0319^{* * *}$ \\
\hline & & $(3,5078)$ & $(5,1692)$ & $(4,8362)$ & $(8,2241)$ \\
\hline \multirow{6}{*}{ 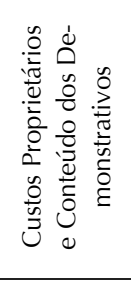 } & \multirow{2}{*}{ Market to Book } & 0,0076 & $-0,0185$ & 0,0483 & 0,0012 \\
\hline & & $(0,1256)$ & $(-0,2018)$ & $(0,4997)$ & $(0,8147)$ \\
\hline & \multirow{2}{*}{ Prejuízo } & $3,1429^{* * *}$ & $2,9607^{* * *}$ & $3,0869^{* * *}$ & $0,0660^{* * *}$ \\
\hline & & $(2,9662)$ & $(3,1866)$ & $(3,4052)$ & $(5,1388)$ \\
\hline & \multirow{2}{*}{ Boa Notícia } & $-0,6064$ & $-0,5305$ & $-0,6466$ & $-0,0114$ \\
\hline & & $(-1,0541)$ & $(-0,8905)$ & $(-1,1074)$ & $(-1,3376)$ \\
\hline \multirow{19}{*}{ 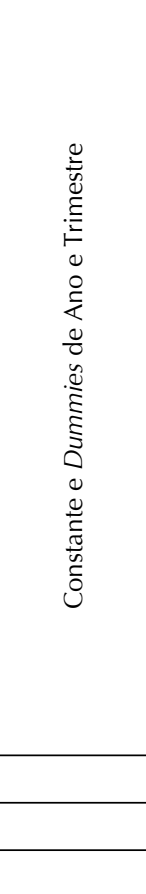 } & Constante & $47,1476^{* * *}$ & $47,0450^{* * *}$ & $35,7712^{* * *}$ & $3,6356^{* * *}$ \\
\hline & Ano 1998 & $-7,2221$ & $-5,8932$ & $-7,0804^{*}$ & $-0,1393 * * *$ \\
\hline & Ano 1999 & $-7,9294^{*}$ & $-7,2009^{*}$ & $-7,6981^{* *}$ & $-0,1504^{* * *}$ \\
\hline & Ano 2000 & $-7,5841^{*}$ & $-6,4549$ & $-7,0765^{* *}$ & $-0,1335^{* * *}$ \\
\hline & Ano 2001 & $-7,1630^{*}$ & $-5,7091$ & $-7,2732^{* *}$ & $-0,1355^{* * *}$ \\
\hline & Ano 2002 & $-8,8893^{* *}$ & $-7,8711^{*}$ & $-8,9428^{* * *}$ & $-0,1687^{* * *}$ \\
\hline & Ano 2003 & $-8,6415^{* *}$ & $-7,4701^{*}$ & $-8,8338^{* *}$ & $-0,1671^{* * *}$ \\
\hline & Ano 2004 & $-9,6932^{* *}$ & $-8,6611^{* *}$ & $-9,9196^{* * *}$ & $-0,1908^{* * *}$ \\
\hline & Ano 2005 & $-10,1552^{* *}$ & $-9,5055^{* *}$ & $-10,6186^{* * *}$ & $-0,2056^{* * *}$ \\
\hline & Ano 2006 & $-10,1957^{* *}$ & $-9,2208^{* *}$ & $-11,0898^{* * *}$ & $-0,2115^{* * *}$ \\
\hline & Ano 2007 & $-12,5987^{* * *}$ & $-11,6789^{* * *}$ & $-13,6468^{* * *}$ & $-0,2719^{* * *}$ \\
\hline & Ano 2008 & $-13,7402^{* * *}$ & $-12,1930^{* * *}$ & $-14,4379^{* * *}$ & $-0,2993 * * *$ \\
\hline & Ano 2009 & $-10,1909 * *$ & $-9,0274^{* *}$ & $-11,1405^{* * *}$ & $-0,2084 * * *$ \\
\hline & $2^{\circ}$ Trim & $-1,0650^{* *}$ & $-1,1574^{*}$ & $-1,0736$ & $-0,0272^{* *}$ \\
\hline & $3^{\circ}$ Trim & $-1,0202 *$ & $-1,0856$ & $-0,9996$ & $-0,0248^{* *}$ \\
\hline & $4^{\circ}$ Trim & $22,7169 * * *$ & $22,6746^{* * *}$ & $22,5609 * * *$ & $0,4533^{* * *}$ \\
\hline & №. Observações & 1585 & 1585 & 1585 & 1585 \\
\hline & R2 (between) & 0,3622 & 0,3531 & & \\
\hline & Rho (AR) & & 0,2317 & & \\
\hline
\end{tabular}

***.** $\mathrm{e}^{*}$ denotam significância estatística aos níveis de $1 \% .5 \%$ e $10 \%$. respectivamente. Estatística $t$ entre parênteses (somente para as principais variáveis).

Entre as variáveis representativas da dimensão complexidade das operações, a única que parece afetar de forma significativa a defasagem na divulgação é a variável demonstrações consolidadas. Seus coeficientes são positivos e estatisticamente significantes ao nível de $1 \%$, independente do estimador utilizado, e coerentes com as expectativas teóricas: demonstrações consolidadas aumentam a complexidade e, portanto, aumentam a defasagem na divulgação.

Com base no coeficiente do modelo de regressão Poisson, o fato de a divulgação referir-se a demonstrativos consolidados aumenta a defasagem esperada em torno de $7 \%$ (ou em aproximadamente 3 dias, utilizando a defasagem média de 44 dias). No que tange às variáveis tamanho e ADR que, assim como setor regulado, não apresentaram coeficientes estatisticamente significantes, é possível que estejam representando dimensões cujos efeitos sobre a defasagem na divulgação são antagônicos (e se anulam): por um lado, grandes companhias e emissoras de ADRs possuem operações e/ou contabilidade mais complexas; por outro lado, tais companhias estão sob maior escrutínio do mercado e, portanto, são impelidas a prover um disclosure tempestivo.

Quanto à dimensão governança corporativa, a variável alavancagem de controle apresentou coeficientes negativos e estatisticamente significantes em três dos quatro estimadores (o nível de significância também difere entre eles). Esse resultado sugere que a prática de um disclosure tempestivo pode, de certa forma, "compensar" uma maior propensão, por parte dos maiores acionistas, a extrair benefícios privados do controle (maior alavancagem), indicando que pode haver uma relação de substituição entre alavancagem de controle e disclosure tempestivo. Com base no coeficiente do modelo de regressão Poisson, uma variação de um desvio-padrão na variável alavancagem de controle diminui a defasagem esperada em aproximadamente 3\% $(-0,0577 \times 0,53 \times 100$, ou aproximadamente 1.4 dias, com base na defasagem média). A variável propriedade privada também apresentou coeficientes negativos, corroborando a expectativa teórica, porém são estatisticamente significantes somente no caso das estimações por efeitos aleatórios. Com base nesses estimadores, uma variação de um desviopadrão na variável propriedade privada diminui a defasagem esperada em cerca de 2 dias $(-8,48 \times 0,24)$. As demais variáveis dessa dimensão não apresentaram coeficientes estatisticamente significantes, sugerindo que a proporção 
de investidores institucionais e a listagem em níveis diferenciados de governança corporativa não são fatores incentivadores da prática de disclosure tempestivo.

Em relação à dimensão assimetria informacional, a variável turnover apresentou coeficientes positivos, contrariando as expectativas teóricas de que um maior volume de negócios, indicador do número de investidores que acompanham mais de perto as operações da companhia, estaria inversamente relacionado a defasagem na divulgação. No entanto, a relação é estatisticamente significante apenas no modelo de regressão Poisson (ao nível de 10\%) e seu efeito econômico é limitado: uma variação de um desvio-padrão na variável turnover aumenta a expectativa da defasagem em torno de $1 \%(0,00002 \times 590,96 \times 100)$.

A variável volatilidade, contrariando as expectativas teóricas, apresentou coeficientes positivos e estatisticamente significantes ao nível de $1 \%$ em todos os estimadores. Com base no coeficiente do modelo de regressão Poisson, uma variação de um desvio-padrão na variável volatilidade aumenta a defasagem esperada em torno de $4 \%(0,0319 \times 1,3$ x 100, ou aproximadamente 1.8 dias, com base na defasagem média). Cabe mencionar que, no estudo de Sengupta (2004), a volatilidade também apresenta efeito positivo e estatisticamente significante sobre a defasagem. É possível que esse fenômeno seja causado pela existência de simultaneidade entre a defasagem na divulgação e a volatilidade dos retornos da firma, como mencionado na seção anterior. Para verificar se a simultaneidade entre essas variáveis afeta as estimativas, estimou-se o modelo pelo método de variáveis instrumentais, cujos detalhes de implementação e principais resultados são discutidos ao final desta seção.

Entre as variáveis representativas da dimensão custos proprietários e conteúdo dos demonstrativos, a variável prejuízo é a única que afeta de forma estatisticamente significante a defasagem na divulgação. Seus coeficientes são positivos e estatisticamente significantes ao nível de $1 \% \mathrm{em}$ todos os estimadores, corroborando a hipótese de que os benefícios de retardar a divulgação de prejuízos ("más notícias") superam possíveis custos associados. Em relação a seus efeitos econômicos, a divulgação de prejuízos aumenta a defasagem esperada em torno de 7\% (ou aproximadamente 2.9 dias, com base na defasagem média), efeito similar à divulgação de demonstrações consolidadas. A variável boa notícia apresentou coeficientes negativos, conforme expectativas, mas estatisticamente insignificantes. A falta de significância estatística dos coeficientes dessa variável pode ter sido causada pela inclusão simultânea da variável prejuízo, proxy para "más notícias". A variável market to book value, proxy para custos proprietários, também não apresentou coeficientes estatisticamente significantes nas regressões. Provavelmente essa variável não é uma proxy adequada $^{7}$ e, para futuros estudos, sugere-se o uso de variáveis indicadoras do grau de concentração no mercado de produtos como proxies para custos proprietários (ver Bamber \& Cheon, 1998).

Os coeficientes estatisticamente significantes das dummies de ano e trimestre reforçam as conclusões obtidas ante- riormente na análise das estatísticas descritivas: i) a defasagem na divulgação vem diminuindo sensivelmente ao longo dos anos, provavelmente em função do progresso tecnológico e da crescente preocupação das companhias em atender as demandas informacionais dos investidores; e ii) o quarto trimestre apresenta maior defasagem quando comparado aos demais. Quanto à qualidade do ajustamento, a Tabela 5 (efeitos aleatórios somente) indica que o modelo proposto apresenta um bom ajustamento aos dados, explicando entre $35 \%$ e $36 \%$ das variações da defasagem na divulgação entre os indivíduos [R2 (between)]. Cabe ainda um comentário relativo à interpretação do coeficiente rho de autocorrelação dos resíduos. O fato de ser positivo e significativo pode indicar que há certa "formação de hábito" com relação à data de divulgação das demonstrações, assunto que merece ser investigado mais profundamente em uma futura pesquisa.

Os métodos até aqui utilizados para estimação do modelo empírico (1) são inconsistentes na presença de simultaneidade entre a variável dependente e qualquer uma das variáveis explicativas. Como discutido anteriormente, é possível que a defasagem na divulgação e a volatilidade dos retornos da firma sejam determinadas simultaneamente. Para obter estimativas consistentes dos parâmetros na presença de simultaneidade entre essas variáveis, estimou-se o modelo empírico por meio do método de variáveis instrumentais. Uma variável é candidata a variável instrumental se satisfaz as seguintes condições ${ }^{8}$ : (i, condição de inclusão) possui um efeito direto sobre a variável explicativa endógena, isto é, controlando para as demais variáveis exógenas, a variável instrumental deve ser parcialmente correlacionada com a variável endógena; e (ii, condição de exclusão) não tem um efeito direto sobre a variável dependente, em outras palavras, a correlação entre o resíduo do modelo (1) e a variável instrumental deve ser igual a zero.

Entre as variáveis determinantes da volatilidade dos retornos, a alavancagem operacional é, provavelmente, a mais apta a satisfazer ambas as condições acima, uma vez que é pouco provável que a alavancagem operacional tenha um efeito direto sobre a defasagem na divulgação das demonstrações contábeis. Dessa forma, optou-se por utilizar essa variável como instrumento para a volatilidade dos retornos. A alavancagem operacional é comumente definida como a variação percentual no lucro operacional dada uma variação percentual na quantidade de vendas e mensura o grau de utilização de custos fixos na estrutura de custos da firma. Dada sua definição, essa variável foi computada por meio da seguinte expressão:

Alavancagem Operacional $=A B S\left(\frac{\Delta E B I T_{i, t} / E B I T_{i, t-1}}{\Delta \text { Receitas }_{i, t} / \text { Receitas }_{i, t-1}}\right)$

Em que $E B I T_{i, t}$ é o lucro antes dos juros e imposto de renda da $i$-ésima firma no trimestre $t$; Receitas $_{i, t}$ é a receita líquida de vendas da $i$-ésima firma no trimestre $t$; e $A B S($ ) é a função valor absoluto. No cálculo da alavancagem operacional presume-se que, tudo o mais constante, variações positivas (negativas) na quantidade de vendas afetem positivamente (negativamente) o lucro operacional. Em função

${ }^{6}$ Estimações do modelo (1) sem a variável prejuízo confirmam essa hipótese. Resultados não reportados, mas disponíveis sob requisição.

${ }^{7}$ Sengupta (2004) também não encontrou relação estatisticamente significante entre a variável market to book value e a defasagem na divulgação das demonstrações contábeis.

${ }^{8}$ Ver Wooldridge (2002, p. 84). 
disso, essa variável foi computada somente para as observações (firma-trimestre) em que o sinal da variação no lucro antes dos juros e imposto de renda era igual ao sinal da variação na receita líquida de vendas, isto é, para as observações em que sinal $\left(\triangle E B I T_{i, t}\right)=\operatorname{sinal}\left(\Delta\right.$ Receitas $\left._{i, t}\right)$.

Uma vez computada a alavancagem operacional ao nível de firma, tomou-se a média dessa variável dentro de cada setor de atividade (em cada trimestre da amostra), de forma a obter uma medida da alavancagem operacional ao nível de setor. $\mathrm{O}$ uso da alavancagem operacional ao nível de setor se justifica pelos seguintes aspectos: (i) a alavancagem operacional é, em grande parte, determinada pelas características do setor (por exemplo, tecnologia); e (ii) evita a perda das observações para as quais não foi possível computar a alavancagem operacional ao nível de firma. Os resultados da estimação do modelo (1) pelo método de variáveis instrumentais com efeitos aleatórios são apresentados na Tabela 6, juntamente com os resultados da regressão de primeiro estágio (colunas 1 e 2).

Tabela 6 Resultados da estimação do modelo empírico por variáveis instrumentais

\begin{tabular}{|c|c|c|c|}
\hline \multicolumn{2}{|c|}{ Regressão de Primeiro Estágio } & \multicolumn{2}{|l|}{ Regressão de Segundo Estágio } \\
\hline Variável Dependente: & Volatilidade & Variável Dependente: & Defasagem \\
\hline \multirow{2}{*}{ Tamanho } & -0.0081 & \multirow{2}{*}{ Tamanho } & 0,5569 \\
\hline & $(-0,15)$ & & $(0,7470)$ \\
\hline \multirow{2}{*}{ Dem. Consolidadas } & $-0,1385$ & \multirow{2}{*}{ Dem. Consolidadas } & $2,7286^{*}$ \\
\hline & $(-1,35)$ & & $(1,6463)$ \\
\hline \multirow{2}{*}{ Setor Regulado } & 0,1070 & \multirow{2}{*}{ Setor Regulado } & 2,2280 \\
\hline & $(0,55)$ & & $(0,8189)$ \\
\hline \multirow{2}{*}{ ADR } & 0,0134 & \multirow{2}{*}{$\mathrm{ADR}$} & $-1,9593$ \\
\hline & $(0,09)$ & & $(-0,9976)$ \\
\hline \multirow{2}{*}{ Nível GC } & $-0,0891$ & \multirow{2}{*}{ Nível GC } & 0,2698 \\
\hline & $(-0,83)$ & & $(0,1689)$ \\
\hline \multirow{2}{*}{ Alavancagem Controle } & $-0,0269$ & \multirow{2}{*}{ Alavancagem Controle } & $-2,2973^{*}$ \\
\hline & $(-0,30)$ & & $(-1,8980)$ \\
\hline \multirow{2}{*}{$\%$ Prop. Institucional } & 0,0812 & \multirow{2}{*}{$\%$ Prop. Institucional } & $-0,8266$ \\
\hline & $(0,27)$ & & $(-0,2015)$ \\
\hline \multirow{2}{*}{ \% Prop. Privada } & 0,0709 & \multirow{2}{*}{ \% Prop. Privada } & $-7,8826^{*}$ \\
\hline & $(0,22)$ & & $(-1,7840)$ \\
\hline \multirow{2}{*}{ Turnover } & $0,0007^{* * *}$ & \multirow{2}{*}{ Turnover } & 0,0060 \\
\hline & $(11,09)$ & & $(1,2261)$ \\
\hline \multirow{2}{*}{ Alavancagem Operacional } & $0,0002 * *$ & \multirow{2}{*}{ Volatilidade } & $-5,5065$ \\
\hline & $(2,08)$ & & $(-0,8446)$ \\
\hline \multirow{2}{*}{ Market to Book } & $-0,0247^{* * *}$ & Market to Book & $-0,1348$ \\
\hline & $(-3,05)$ & 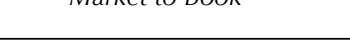 & $(-0,6826)$ \\
\hline Рreiúź & $0,4125^{* * *}$ & Рreiúzo & $6,0955^{* *}$ \\
\hline 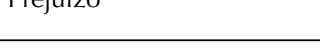 & $(5,06)$ & Tाejurzo & $(2,0536)$ \\
\hline Boa Notícia & $-0,0247$ & Boa Notícia & $-0,4801$ \\
\hline Dua tivelicia & $(-0,45)$ & Dua tivericia & $(-0,6276)$ \\
\hline Constante & $3,3502^{* * *}$ & Constante & $63,5954^{* *}$ \\
\hline Ano 1998 & $0,8419^{* *}$ & Ano 1998 & 1,6160 \\
\hline Ano 1999 & 0,4460 & Ano 1999 & $-1,4864$ \\
\hline Ano 2000 & $-0,2843$ & Ano 2000 & $-7,1799$ \\
\hline Ano 2001 & $-0,1734$ & Ano 2001 & $-6,1300$ \\
\hline Ano 2002 & $-0,4965$ & Ano 2002 & $-10,1386$ \\
\hline Ano 2003 & $-1,0504^{* * *}$ & Ano 2003 & $-13,9415$ \\
\hline Ano 2004 & $-0,9293^{* *}$ & Ano 2004 & $-14,4281^{*}$ \\
\hline Ano 2005 & $-0,8499 * *$ & Ano 2005 & $-14,2188^{*}$ \\
\hline Ano 2006 & $-1,0846^{* * *}$ & Ano 2006 & $-15,9299 *$ \\
\hline Ano 2007 & $-0,9726^{* *}$ & Ano 2007 & $-17,7778^{* *}$ \\
\hline Ano 2008 & 0,2075 & Ano 2008 & $-10,3772^{*}$ \\
\hline Ano 2009 & $-0,5741$ & Ano 2009 & $-12,2948^{*}$ \\
\hline $2^{\circ}$ Trim & $-0,3061^{* * *}$ & $2^{\circ}$ Trim & $-3,3439$ \\
\hline $3^{\circ}$ Trim & $-0,1344^{*}$ & $3^{\circ}$ Trim & $-1,8930$ \\
\hline $4^{\circ}$ Trim & $0,1670^{* *}$ & $4^{\circ}$ Trim & $25,6330^{* * *}$ \\
\hline №. Observações & 1364 & №. Observações & 1364 \\
\hline Wald (chi2(28)) & 662,0 & R2 (overall) & 0,3441 \\
\hline Prob > chi2 & 0,0000 & R2 (within) & 0,4519 \\
\hline & & R2 (between) & 0,1310 \\
\hline
\end{tabular}


$\mathrm{Na}$ regressão de primeiro estágio, em que a variável dependente é a volatilidade dos retornos, a variável alavancagem operacional apresenta coeficiente positivo e estatisticamente significante ao nível de 5\%, corroborando a expectativa teórica de uma relação positiva entre a alavancagem operacional e a volatilidade dos retornos da firma. A existência de um efeito direto da alavancagem operacional sobre a volatilidade é condição necessária (mas não suficiente) para o uso dessa variável como instrumento para a volatilidade (condição de inclusão). Na regressão de segundo estágio, em que a variável dependente é a defasagem na divulgação e a variável alavancagem operacional é utilizada como instrumento para a volatilidade dos retornos, podese observar que, com exceção da variável volatilidade, há poucas diferenças em relação aos resultados anteriores (ver Tabela 5, coluna Efeitos Aleatórios). Embora o nível de significância estatística não seja exatamente o mesmo, as variáveis demonstrações consolidadas, alavancagem de controle, propriedade privada e prejuízo apresentam coeficientes estatisticamente significantes e com o mesmo sinal que apresentaram na estimação anterior. A variável volatilidade, por outro lado, apresenta coeficiente negativo (antes positivo) e, dessa forma, consistente com as expectativas a priori, mas estatisticamente não diferente de zero. A inversão do sinal do coeficiente da variável volatilidade sugere que ignorar a simultaneidade entre essa variável e a defasagem na divulgação conduz a estimativas viesadas e a conclusões equivocadas acerca do efeito da volatilidade dos retornos sobre a defasagem na divulgação das demonstrações contábeis.

\section{CONSIDERAÇÕES FINAIS}

Este artigo propôs-se a investigar os fatores determinantes da defasagem na divulgação das demonstrações contábeis, tema de pesquisa ainda incipiente no Brasil. Para tal, foram definidas, com base em uma revisão da literatura, quatro dimensões que potencialmente afetam a defasagem na divulgação: i) complexidade das operações da companhia; ii) características de governança corporativa; iii) nível de assimetria informacional no mercado acionário; e iv) custos proprietários e conteúdo dos demonstrativos. Tais dimensões foram representadas por 13 variáveis explicativas incluídas em um modelo empírico em que a variável dependente é a defasagem na divulgação.

Com uma amostra de 1585 observações de 83 diferentes companhias, representativas do mercado de capitais brasileiro, o modelo empírico foi estimado utilizando-se métodos de dados em painel. Os principais resultados encontrados sugerem que a divulgação de demonstrativos consolidados e/ou que reportam prejuízos impacta positivamente a defasagem esperada, corroborando as hipóteses de que a maior complexidade das operações e o conteúdo dos demonstrativos (nesse caso, "más notícias") afetam positivamente a defasagem na divulgação das demonstrações contábeis. A variável alavancagem de controle, por sua vez, mostrou-se negativamente relacionada à defasagem, sugerindo que pode haver uma relação de substituição entre alavancagem de controle e disclosure tempestivo. Contrariando as expectativas teóricas, a variável volatilidade apresentou coeficientes positivos e estatisticamente significantes. É possível que esse fenômeno tenha sido causado por um problema de simultaneidade entre a volatilidade e a defasagem na divulgação. Ao utilizar o método de variáveis instrumentais para obter estimativas consistentes na presença de simultaneidade entre a volatilidade e a defasagem na divulgação, a variável volatilidade apresentou coeficiente negativo e estatisticamente não diferente de zero. A inversão do sinal do coeficiente da variável volatilidade sugere que ignorar a simultaneidade entre as variáveis conduz a estimativas viesadas e a conclusões equivocadas acerca do efeito da volatilidade dos retornos sobre a defasagem na divulgação das demonstrações contábeis.

Os resultados encontrados no presente estudo permitem concluir que a escolha, por parte dos gestores, da data de divulgação dos demonstrativos contábeis não é feita "ao acaso" e que benefícios e custos associados à escolha parecem desempenhar um papel relevante, como argumenta a literatura acerca do disclosure corporativo. Pode-se argumentar também que tais custos e benefícios estão relacionados às dimensões anteriormente definidas. Considerando os incentivos e custos que as empresas têm para divulgar tempestivamente suas informações contábeis, os resultados da pesquisa são importantes para sinalizar aos investidores que as decisões das empresas parecem seguir uma racionalidade, buscando inclusive explorar fatores comportamentais dos investidores.

Os resultados da presente pesquisa também apontam que, ao longo do período compreendido, a defasagem temporal média na divulgação das demonstrações contábeis diminuiu consideravelmente (1997: 56 dias; 2009: 40 dias). Esse resultado, em si, reflete um potencial aumento na qualidade da informação contábil, visto que, quanto mais rápida for a divulgação dos números contábeis das empresas, menores tendem a ser as incertezas dos usuários.

As limitações desta pesquisa dizem respeito, principalmente, a indisponibilidade de dados para operacionalização de variáveis identificadas pela literatura como potenciais determinantes da defasagem na divulgação, tais como: previsão de lucros dos analistas, número de analistas seguindo a companhia e número de conselheiros independentes. Adicionalmente, sugere-se, para pesquisas futuras, a inclusão de variáveis de controle que considerem os aspectos referentes à auditoria externa das empresas. A literatura contempla evidências empíricas que relacionam o conteúdo dos pareceres de auditoria (com ou sem ressalva) com uma maior ou menor defasagem na divulgação das demonstrações contábeis. 
Referências

Akerlof, G. (1970, August).The markets for 'lemons': quality uncertainly and the market mechanism. The Quarterly Journal of Economics, 84 (3), 488-500.

Alencar, R. C. (2005, January/June). Custo do capital próprio e nível de disclosure nas empresas brasileiras. Brazilian Business Review, 2 (1), $1-12$.

Bailey, W., Karolyi, G. A., \& Salva, C. (2006, July).The economic consequences of increased disclosure: evidence from international cross-listings. Journal of Financial Economics, 81 (1), 175-213.

Baiman, S., \& Verrecchia, R. (1996, Spring).The relation among capital markets, financial disclosure, production efficiency, and insider trading. Journal of Accounting Research, 34 (1), 1-22.

Ball, R., \& Brown, P. (1968, Autumn). An empirical evaluation of accounting income numbers. Journal of Accounting Research, 6 (2), 159-178.

Bamber, L. S., \& Cheon, Y. S. (1998, Autumn). Discretionary management earnings forecast disclosures: antecedents and outcomes associated with forecast venue and forecast especificity choices. Journal of Accounting Research, 36 (2), 167-190.

Beaver, W. H. (1981, Spring). Econometric properties of alternative security return methods. Journal of Accounting Research, 19 (1), 163-184.

Begley, J., \& Fischer, P. (1998, December). Is there information in an earnings announcement delay? Review of Accounting Studies, 3 (4), 347-363.

BM\&FBovespa. Indice BOVESPA - IBOVESPA. Recuperado em 30 março, 2010, de http://www.bmfbovespa.com.br/indices/ResumoIndice. aspx? Indice=IBOVESPA\&Idioma $=$ pt-BR.

Botosan, C. (1997, July). Disclosure level and the cost of equity capital. The Accounting Review, 72 (3), 323-349.

Botosan, C., \& Plumlee, M. (2002, March). A re-examination of disclosure level and the expected cost of equity capital. Journal of Accounting Research, 40 (1), 21-41.

Brown, S. J., \& Warner, J. B. (1980, September). Measuring security price performance. Journal of Financial Economics, 8 (3), 205-258.

Brown, S. J., \& Warner, J. B. (1985, March). Using daily stock returns: the case of event studies. Journal of Financial Economics, 14 (1), 3-31.

Chambers, A. E., \& Penman, S. H. (1984, Spring). Timeliness of reporting and the stock price reaction to earnings announcements: Journal of Accounting Research, 23 (1), 21-47.

Diamond, D., \& Verrecchia, R. (1991, September). Disclosure, liquidity, and the cost of capital. Journal of Finance, 46 (4), 1325-1359.

Dyck, A., \& Zingales, L. (2004, April). Private benefits of control: an international comparison. Journal of Finance, 59 (2), 537-600.

Easley, D., Hvidkjaer S., \& O'Hara, M. (2002, Autumn). Is information risk a determinant of asset returns? Journal of Finance, 57 (5), 2185-2221.

Easley, D., \& O'Hara, M. (2004, August). Information and the cost of capital. Journal of Finance, 59 (4), 1553-1583.

Givoly, D., \& Palmon, D. (1982, July). Timeliness of annual earnings announcements: some empirical evidence. The Accounting Review, 57 (3), 486-508.

Healy, P. M., Hutton, A., \& Palepu, K. (1999, Autumn). Stock performance and intermediation changes surrounding sustained increases in disclosure. Contemporary Accounting Research, 16 (3), 485-520.

Healy, P. M., \& Palepu, K. G. (2001, September). Information asymmetry, corporate disclosure, and the capital markets: a review of the empirical disclosure literature. Journal of Accounting and Economics, 31 (1-3), 405-440.

Instrução CVM n. 480, de 7 de dezembro de 2009. (2009, December, 9). Dispõe sobre o registro de emissores de valores mobiliários admitidos à negociação em mercados regulamentados de valores mobiliários. Brasília, DF, Diário Oficial da União, 147 (235), Seção I, 28-37.

Kim, O., \& Verrecchia, R. (1994, January). Market liquidity and volume around earnings announcements. Journal of Accounting and Economics, 17 (1-2), 41-68.

Kross, W. (1981, September). Earnings and announcement time lags. Journal of Business Research, 9 (3), 267-281.

Lambert, R., Leuz, C., \& Verrecchia, R. (2007, May). Accounting information, disclosure, and the cost of capital. Journal of Accounting Research, 45 (2), 385-420.

Leal, R. P. C., \& Saito, R. (2003, July/December). Finanças corporativas no Brasil. RAE eletrônica [online], 2 (2), 2-15.

Leuz, C., \& Verrecchia, R. (2000). The economic consequences of increased disclosure. Journal of Accounting Research, (Supplement: Studies on Accounting Information and the Economics of the Firm), $38,91-124$

Lima, G. A. S. F. (2009, Janeiro/Abril). Nível de evidenciação x custo da dívida das empresas brasileiras. Revista Contabilidade \& Finanças, 20 (49), 95-108.

Lima, J. B. N., \& Terra, P. R. S. (2005). A reação do mercado de capitais brasileiro à divulgação das informações contábeis. In Varga, G., \& Leal, R. P. C. (Org.). Gestão de investimentos e fundos. (pp. 199-216). Rio de Janeiro: FCE.

Lopes, A. B. (2002). A informação contábil e o mercado de capitais. São Paulo: Thomson.

Malacrida, M. J. C., \& Yamamoto, M. M. (2006, Setembro). Governança corporativa: nível de evidenciação das informações e sua relação com a volatilidade das ações do Ibovespa. Revista Contabilidade \& Finanças, Ed. Comemorativa, 65-79.

Prux Jr, J. L. (1998). Assimetria informacional e precificação das ações das empresas negociadas na Bolsa de Valores de São Paulo: evidências a partir da faculdade de divulgar demonstraçoes contábeis em moeda constante a partir de 1996. Dissertação de mestrado em Administração, Programa de Pós Graduação em Administração, Universidade Federal do Rio Grande do Sul, Porto Alegre, Rio Grande do Sul, Brasil.

Schiehll, E. (1996). O efeito da divulgação das demonstrações financeiras no mercado de capitais brasileiro: um estudo sobre a variação no preço das ações. Dissertação de mestrado em Administração, Programa de PósGraduação em Administração, Universidade Federal do Rio Grande do Sul, Porto Alegre, Rio Grande do Sul, Brasil.

Sengupta, P. (2004, November/December). Disclosure timing: determinants of quarterly earnings release dates. Journal of Accounting and Public Policy, 23 (6), 457-482.

Skinner, D. (1994, Spring). Why firms voluntarily disclose bad-news. Journal of Accounting Research, 32 (1), 38-61.

Terra, P. R. S., \& Lima, J. B. N. (2006, September/December). Governança corporativa e a reação do mercado de capitais à divulgação das informações contábeis. Revista Contabilidade \& Finanças, 17 (42).

Velury, U., \& Jenkins, D. S. (2006, September). Institutional ownership and the quality of earnings. Journal of Business Research, 59 (9), 1043-1051.

Verrecchia, R. (1983). Discretionary disclosure. Journal of Accounting \& Economics, 5, 179-194.

Verrecchia, R. (1990, March). Information quality and discretionary disclosure. Journal of Accounting \& Economics, 12 (4), 365-380.

Whittred, G. (1980, October). Audit qualification and the timeliness of corporate annual reports. The Accounting Review, 55 (4), 563-77.

Wooldridge, J. M. (2002). Econometric analysis of cross section and panel data. Cambridge: The MIT Press. 